\title{
Describing socioeconomic gradients in children's diets - does the socioeconomic indicator used matter?
}

\author{
Dorota Zarnowiecki ${ }^{*}$, Kylie Ball ${ }^{2}$, Natalie Parletta ${ }^{1}$ and James Dollman ${ }^{3}$
}

\begin{abstract}
Background: Children of low socioeconomic position (SEP) generally have poorer diets than children of high SEP. However there is no consensus on which SEP variable is most indicative of SEP differences in children's diets. This study investigated associations between diet and various SEP indicators among children aged 9-13 years.

Method: Families $(n=625)$ were recruited from 27 Adelaide primary schools in 2010. Children completed semi-quantitative food frequency questionnaires providing intake scores for fruit, vegetables, non-core foods, sweetened drinks, and healthy and unhealthy eating behaviours. Parents reported demographic information by telephone interview. Differences in dietary intake scores were compared across parental education, income, occupation, employment status and home postcode.

Results: Across most SEP indicators, lower SEP was associated with poorer dietary outcomes, including higher intake of non-core foods and sweetened drinks, and more unhealthy behaviours; and lower intake of fruit and vegetables, and fewer healthy behaviours. The number and type of significant SEP-diet associations differed across SEP indicators and dietary outcomes. Mother's education appeared most frequently as a predictor of children's dietary intake, and postcode was the least frequent predictor of children's dietary intake.

Conclusion: Socioeconomic gradients in children's dietary intake varied according to the SEP indicator used, suggesting indicator-specific pathways of influence on children's dietary intake. Researchers should consider multiple indicators when defining SEP in relation to children's eating.
\end{abstract}

Keywords: Socioeconomic position, Children, Diet, Fruit, Vegetables, Non-core food, Sweet drinks

\section{Background}

A relatively consistent body of literature shows that children and adolescents of low socioeconomic position (SEP) are at risk of consuming poorer diets, due to lower fruit and vegetable consumption [1-3], and higher intake of snack foods, fast foods and sweetened beverages [3-5]. These types of dietary patterns may contribute to higher energy and fat intake among children of low SEP [6], higher obesity rates [7], and higher rates of cardiovascular disease in later life [8]. The drivers of these SEP gradients in children's diets are not well understood. One reason for this may be that it is unclear what aspects of

\footnotetext{
* Correspondence: dorota.zarnowiecki@unisa.edu.au

${ }^{1}$ School of Population Health, University of South Australia, GPO Box 2471, Adelaide, SA 5001, Australia

Full list of author information is available at the end of the article
}

SEP are most important or how different SEP indicators might be differentially associated with diet. A better understanding of this would give insights into potential mechanisms by which socioeconomic disadvantage leads to poorer dietary intake.

A range of SEP indicators have been used to identify associations of SEP with children's diet. Parent education, occupation and income are the most frequently used SEP indicators [1,9]. In addition to these, SEP has been defined using census data as an indicator of neighbourhood disadvantage $[4,10,11]$, receipt of reduced cost or free school meals $[12,13]$, and perceived family affluence defined by factors such as internet access and car ownership [14,15]. Composite scores of SEP combining multiple socioeconomic indicators have also been used $[16,17]$. Most studies define SEP using one socioeconomic

\section{Biomed Central}

(c) 2014 Zarnowiecki et al.; licensee BioMed Central Ltd. This is an Open Access article distributed under the terms of the Creative Commons Attribution License (http://creativecommons.org/licenses/by/2.0), which permits unrestricted use, distribution, and reproduction in any medium, provided the original work is properly credited. 
indicator (for example, $[13,18,19]$ ), however SEP is the product of a number of social and economic factors [20], and several indicators may be needed to more confidently characterise SEP disparities in children's dietary intake [21].

Limited evidence suggests that SEP indicators may be both independently and synergistically associated with children's diet. Vereecken et al. [22] simultaneously modeled the effects, firstly, of occupation and family affluence on adolescents' fruit and soft drink intake, and secondly, the effect of family affluence, occupation and school-level affluence. Adolescents from families of higher affluence and parental occupation status consumed more fruit, and those with parents of high occupation status consumed less soft-drink. These gradients were maintained but slightly attenuated by the inclusion of the area-level measures in the final models, indicating that all three indicators independently contributed to explaining differences in children's fruit and soft drink intake. Both maternal education and area-level SEP were independently related with "unhealthy eating" and "unhealthy snacking" patterns of 11-year old children, when included simultaneously in adjusted models [23]. The influence of SEP indicators may also differ for boys and girls. In multivariate models including seven SEP indicators, maternal education and family affluence independently predicted adolescent girls' breakfast consumption, whereas only perceived family wealth predicted boys' breakfast consumption [14]. Few other studies have simultaneously modeled associations of a number of socioeconomic indicators with diet in youth. Among adults, Lakulla and colleagues [21] modeled multiple SEP indicators in relation to a composite dietary intake score of healthy food habits in Finnish adults. In final models including all seven SEP indicators, significant associations remained between each indicator of low SEP and less healthy food habits; however these relationships were attenuated compared with initial independent models for SEP indices. Galobardes et al. [24] modeled interactions between education and occupation, showing a significant additive effect on men's starchy carbohydrate consumption (pasta and potatoes), whereby consumption increased by education level within each occupation group, with highest consumption among men who were of both low occupation and low education.

These studies highlight the complexity of conceptualizing SEP in health research, and suggest that SEP indicators are not interchangeable but are each operationally distinct and may influence health behaviours by conceptually different processes [25]. While this issue has been considered in a number of studies of adults [21,24-26], there has been less consideration of how different SEP indicators influence children's dietary intake. A better understanding of the independent contributions of various indicators of SEP to children's diets will help shed light on both the most vulnerable target groups, and potential underlying mechanisms for health promotion. Therefore, the aim of this study was to investigate the strength and independence of the associations between children's dietary intake and various indicators of SEP (education, occupation, employment status, income, and postcode).

\section{Methods}

This was a cross-sectional study conducted in Adelaide, South Australia from March to November 2010, involving children aged 9-13 years and their parents. Ethics approval was obtained from the University of South Australia Human Research Ethics Committee and the Department of Education and Children's Services Ethics Committee. Parents provided written consent for their family to participate in the study, and children provided verbal assent before commencing study measures.

\section{Participant recruitment}

Participants were recruited from grades five to seven of Government primary schools in metropolitan Adelaide. In Australia, parents may choose to send children to government, independent or Catholic schools. In this study, we recruited from government schools which children from across all socioeconomic strata attend. Schools were divided into tertiles by SEP using the School Card Register (SCR), which ranks schools according to the percentage of students receiving means-tested Government assistance to meet the cost of school attendance. Schools were randomly selected from each tertile and study information was sent by email to the school Principal. Recruitment started in March 2010, and continued until September 2010 simultaneously with data collection. This allowed the number of participants completing the study from each SEP tertile to be monitored and more schools to be recruited from the required SEP tertile to ensure an even distribution of participants across socioeconomic strata. Eighty-four schools were sent information about the study, of which 27 agreed to participate (32\% response rate). Ten of these schools were low SEP, six mid SEP and 11 high SEP according to the SCR, with a significantly lower response rate of $28 \%$ in low SEP schools $(\mathrm{p}<0.000)$.

Participating schools distributed study information sheets and consent forms to parents of students in participating classes. Information was distributed to 2575 students, of which 1257 returned consent forms indicating consent to participate in the study $(48.8 \%$ response rate), and 1201 students completed the study measures (95.6\% of participating students). Children were excluded from participation if they had chronic conditions affecting dietary intake or seriously limiting their ability to complete study measures, and if they or 
their parents were unable to speak and understand English with sufficient fluency to complete study measures. Of the 1201 participants, 625 are included in this analysis as they had both complete food intake data (from phase 1) and parent-reported demographic information (from phase 2 CATI). Demographic information was not collected from participants who did not complete the CATI, and therefore it was not possible to analyse whether there were any differences between those and parents who are included in this analysis. However, children whose parents completed the CATI were significantly more likely to live in a neighbourhood of higher SEP (determined using the SEIFA index described below), but there was no difference in children's age, sex or dietary outcomes.

\section{Procedure}

The study was conducted over two phases: in the first phase children completed the Child Nutrition Questionnaire $(\mathrm{CNQ})$, and in the second phase parents completed a 'computer-assisted telephone interview' (CATI). The CNQ was completed by children online using school computer facilities during school hours. Groups of 15 to 30 students were supervised during questionnaire completion by three to four research assistants. At completion of phase one, parents were invited by telephone call to complete the CATI if their child had complete survey data. The CATI was conducted by trained interviewers with the parent primarily responsible for their child's food provision and lasted 15-20 minutes. During the CATI parents responded to questions about predictors of children's health behaviours and demographic information about the family.

\section{Study measures}

Children's dietary intake was measured using the Child Nutrition Questionnaire (CNQ), a semi-quantitative food frequency questionnaire designed to measure dietary patterns associated with positive energy consumption [27]. The CNQ provided six scores of dietary intake and eating behaviours, capturing usual patterns of children's consumption of fruits, vegetables, non-core foods, sweetened beverages and healthy and unhealthy eating behaviours. Dietary intake scores were formed by summing scores on individual responses, with questions about weekly intake recoded to represent daily intake for consistency between items. Details about questions, score structure and psychometric properties are provided in Table 1 and have been previously described [27]. Validity and reliability of the CNQ were determined to be acceptable by Wilson et al. [27], and similar to other instruments measuring dietary intake in this age group $[28,29]$.

Parents reported demographic information about mother's education, occupation, household income, home postcode and parent age and marital status (used as covariates in data analysis). Maternal demographic characteristics were used as mothers are likely to be the gatekeepers to family food environments, and as such maternal socioeconomic factors may more directly impact children's dietary habits than paternal socioeconomic factors $[1,30]$. Mother's education level was reported on an eight point scale ranging from (1) never attended school to (8) completed postgraduate education. Parents reported mother's job title, and this information was coded using the Australian and New Zealand Standard Classification of Occupations (ANZSCO) which groups occupations into eight hierarchical tiers according to level of skills, education, responsibility and experience required to perform the occupation [31]. An additional category was created for individuals 'not in the labour force', comprised of individuals engaged in full-time home duties, retired persons, unemployed and students. Where insufficient information was provided in the job title to accurately classify an individual, for example 'public servant', these data points were not coded and were treated as missing data. Additionally, mother's employment status was dichotomised into employed, and not in the labour force. Gross household income per annum before tax, including pensions and government assistance, was reported using seven income brackets ranging from (1) Up to AU $\$ 12,000$ to (7) More than AU\$100,000. Home postcodes were classified into tertiles of SEP using the Socioeconomic Index for Areas (SEIFA) score of disadvantage, an area-level index of disadvantage based on census data for factors such as income, education and occupation (Australian Bureau of Statistics, 2008).

\section{Data analysis}

Demographic information collected from parents was matched with children's responses to the CNQ. If one or more items within a dietary outcome score were missing, the score for that participant was not calculated. Initial linear models were constructed, adjusted and unadjusted for clustering by class and school, finding no evidence of clustering of dietary variables in classes within schools. All analyses were conducted separately for boys and girls as SEP associations with diet may differ between boys and girls [18]. SPSS version 19 was used to generate descriptive statistics and conduct independent samples $\mathrm{t}$-tests to compare differences in dietary intake between boys and girls.

Correlated component regression (CCR) was used to identify socioeconomic predictors of dietary outcomes. All SEP variables (mother's education, income, mother's occupation, employment status, and SEIFA) were entered simultaneously into the CCR model along with possible covariates of child age, mother's age and marital status. CCR employs cross-validation with a step-down 
Table 1 Summary of questions and mean intake scores from Child Nutrition Questionnaire

\begin{tabular}{|c|c|c|c|c|c|c|}
\hline Scale & Items & Response & $\begin{array}{l}\text { Score } \\
\text { range }\end{array}$ & $\begin{array}{l}\text { Target healthy } \\
\text { value }^{\#}\end{array}$ & $\begin{array}{l}\text { Boys }(n=275) \\
\text { Mean (SD) }\end{array}$ & $\begin{array}{c}\text { Girls }(n=353) \\
\text { Mean (SD) }\end{array}$ \\
\hline Fruit intake (3-items) & $\begin{array}{l}\text { (1) Consumption of fruit at recess/ } \\
\text { lunch/after school, (2) Variety of } \\
\text { fruits consumed yesterday, } \\
\text { (3) Usual serves of fruit per day }\end{array}$ & $\begin{array}{l}\text { (1-2) Tick if consumed; } \\
\text { (3) Frequency scale }{ }^{a}\end{array}$ & $0-16$ & $\geq 6$ & $5.44(2.92)$ & $5.35(2.62)$ \\
\hline $\begin{array}{l}\text { Vegetable intake } \\
\text { (3-items) }\end{array}$ & $\begin{array}{l}\text { (1) Consumption of vegetables at } \\
\text { recess/lunch/after school, ( } 2 \text { ) variety } \\
\text { of vegetables consumed yesterday, } \\
\text { (3) usual serves of vegetables per day }\end{array}$ & $\begin{array}{l}\text { (1-2) Tick if consumed; } \\
\text { (3) Frequency scale }\end{array}$ & $0-13$ & $\geq 8$ & $4.72(2.40)$ & $4.71(2.40)$ \\
\hline $\begin{array}{l}\text { Non-core food } \\
\text { intake (2-items) }\end{array}$ & $\begin{array}{l}\text { (1) Consumption of } 11 \text { non-core foods } \\
\text { at recess/lunch/after school, (2) No. } \\
\text { times/week non-core foods consumed }\end{array}$ & $\begin{array}{l}\text { (1) Tick if consumed; } \\
\text { (2) Frequency scale }{ }^{b}\end{array}$ & $0-33$ & $\leq 1$ & $3.56(2.33)$ & $3.69(1.91)$ \\
\hline $\begin{array}{l}\text { Sweet drink intake } \\
\text { (2-items) }\end{array}$ & $\begin{array}{l}\text { (1) Consumption of sweet drinks (incl. juice) } \\
\text { at recess/lunch/after school, (2) No. times/ } \\
\text { week sweet drinks consumed }\end{array}$ & $\begin{array}{l}\text { (1) Tick if consumed; } \\
\text { (2) Frequency scale }{ }^{b}\end{array}$ & $0-14$ & $\leq 1.3$ & $1.75(1.35)$ & $1.67(1.27)$ \\
\hline $\begin{array}{l}\text { Healthy behaviours } \\
\text { (5-items) }\end{array}$ & $\begin{array}{l}\text { No. times p/week: (1) Eat breakfast, (2) Carry } \\
\text { water bottle, (3) Help with groceries, (4) Help } \\
\text { prepare dinner, (5) Eat dinner with family }\end{array}$ & Frequency scale $e^{c}$ & $4-20$ & $\mathrm{n} / \mathrm{a}$ & $17.42^{*}(3.57)$ & $18.42^{*}(3.68)$ \\
\hline $\begin{array}{l}\text { Unhealthy behaviours } \\
\text { (3-items) }\end{array}$ & $\begin{array}{l}\text { No. times p/week: (1) Eat dinner in front } \\
\text { of TV, (2) Eat snacks in front of TV, } \\
\text { (3) Eat fast food }\end{array}$ & Frequency scale $e^{c}$ & $3-15$ & $\mathrm{n} / \mathrm{a}$ & $7.64(2.84)$ & $7.68(2.58)$ \\
\hline \multicolumn{7}{|c|}{ 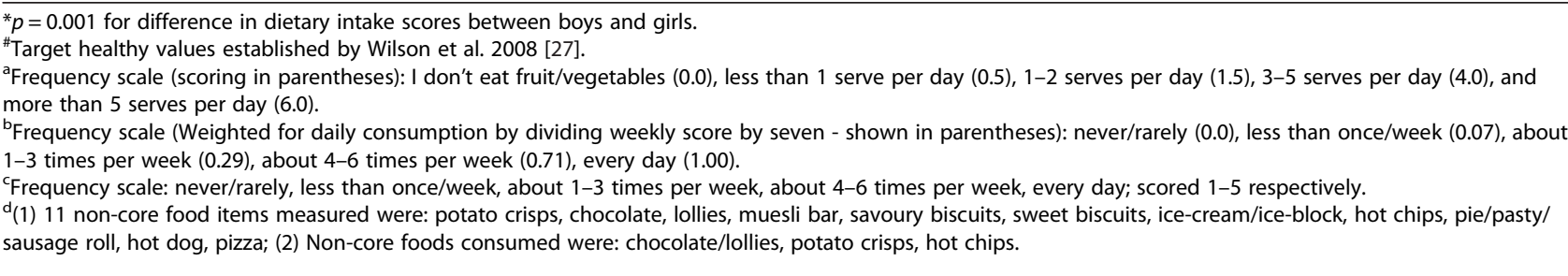 } \\
\hline
\end{tabular}

algorithm to reduce the number of predictors in the model, producing a linear combination of explanatory variables used to predict a function of the dependent variable [32]. The final CCR models reflect the predictors maximising the R-squared and variance explained by the predicting equation. CCR was used as it allows for simultaneous consideration of multiple SEP variables which have mixed scale types and may be correlated, as would be expected with variables representing SEP. Variable importance was compared using both standardized regression coefficients $(\beta)$ and cross-validation predictor counts that reflect the number of occasions the variable appeared as a predictor in regression models. CCR analyses were conducted using XLSTAT 2012.

\section{Results}

\section{Demographic and descriptive data}

Complete dietary intake data and demographic information were collected from 625 child-parent dyads (Tables 1 and 2). The mean age of participating children was 11.3 years and 56\% were girls. Participating families were well distributed across the socioeconomic strata for all SEP indicators. Table 1 presents the means and standard deviations for dietary intake scores stratified by sex. Dietary intake scores were similar for boys and girls except for the healthy behaviour score, which was significantly higher in girls. Comparison of dietary intake scores from the CNQ with dietary guidelines is limited. To enable evaluation of the CNQ dietary intake scores, target healthy values have been established for these scores based on Australian dietary guidelines as listed in Table 1 [27]. Mean vegetable intake scores were considerably lower than the target healthy value, and non-core food intake scores were almost four times greater than the target value. Encouragingly, mean sweetened drink intake scores exceeded the target healthy value by only a small amount.

Children's reports of usual serves of fruit and vegetables consumed each day largely fell short of Australian dietary recommendations, particularly for older children. In this study, $86.9 \%$ of boys and $88.7 \%$ of girls aged 9-11 years consumed at least 1-2 serves of fruit daily as per recommendation, and $35.6 \%$ of boys and $33.3 \%$ of girls aged $12-13$ years met the guideline of 3-4 serves of fruit daily [33]. The vegetable intake recommendation of 3 serves daily for children aged 911 years was met by $42.4 \%$ of boys and $40.2 \%$ of girls. The recommendation of at least 4 serves of vegetables daily was met by $39.6 \%$ of boys and $40.9 \%$ of girls aged 12-13 years. 
Table 2 Demographic characteristics of participants

\begin{tabular}{|c|c|c|c|}
\hline & All $(n=628)$ & Boys $(n=275)$ & Girls $(n=353)$ \\
\hline Child age (years) & $11.3(0.90)$ & $11.4(0.89)$ & $11.3(0.90)$ \\
\hline \multicolumn{4}{|l|}{ School grade (\%) } \\
\hline Grade 5 & 26.2 & 26.6 & 26.0 \\
\hline Grade 6 & 39.9 & 38.3 & 41.2 \\
\hline Grade 7 & 33.9 & 35.0 & 32.8 \\
\hline Parent age (years) & $42.1(5.54)$ & $42.3(5.30)$ & $42.0(5.70)$ \\
\hline \multicolumn{4}{|l|}{ Marital status (\%) } \\
\hline Partner & 78.2 & 76.2 & 79.9 \\
\hline No partner & 21.8 & 23.8 & 20.1 \\
\hline \multicolumn{4}{|l|}{ Mother's education level ${ }^{a}(\%)$} \\
\hline Never attended school & 0.2 & 0.0 & 0.3 \\
\hline Some high school & 22.9 & 22.3 & 23.4 \\
\hline Completed high school & 19.1 & 18.2 & 19.8 \\
\hline Trade or diploma & 26.9 & 24.5 & 28.5 \\
\hline University degree & 19.2 & 22.3 & 16.9 \\
\hline Higher University degree & 11.8 & 12.8 & 11.0 \\
\hline \multicolumn{4}{|l|}{ Gross household income ${ }^{\mathrm{bc}}(\%)$} \\
\hline Low & 33.9 & 31.9 & 35.2 \\
\hline Mid & 37.4 & 39.2 & 36.1 \\
\hline High & 28.7 & 28.8 & 28.6 \\
\hline \multicolumn{4}{|l|}{ SEIFA $^{d}(\%)$} \\
\hline Low & 33.5 & 31.8 & 35.0 \\
\hline Mid & 31.8 & 32.8 & 30.8 \\
\hline High & 34.7 & 35.4 & 34.2 \\
\hline \multicolumn{4}{|l|}{ Mother's occupation $^{\mathrm{e}, \mathrm{f}}(\%)$} \\
\hline Managers & 7.0 & 5.9 & 7.8 \\
\hline Professionals & 22.5 & 24.8 & 20.8 \\
\hline Technicians and trades & 4.4 & 4.8 & 4.0 \\
\hline Community and personal service & 11.5 & 12.2 & 11.0 \\
\hline Clerical and administrative & 21.6 & 20.7 & 22.0 \\
\hline Sales & 4.7 & 6.7 & 3.2 \\
\hline Machinery operators and drivers & 0.3 & 0.4 & 0.3 \\
\hline Labourers & 4.9 & 5.9 & 4.0 \\
\hline Not in the labour force & 21.2 & 17.4 & 24.3 \\
\hline \multicolumn{4}{|l|}{ Mother's employment (\%) } \\
\hline Not in the labour force & 21.7 & 17.6 & 24.9 \\
\hline Employed & 78.3 & 82.4 & 75.1 \\
\hline
\end{tabular}

Data reported as percentage (\%) where indicated, or as mean (standard deviation).

${ }^{a}$ Education level measured on an 8-point scale (never attended school - higher university degree) - no participants recorded for responses 'completed some primary school' and 'completed primary school' so these are not reported in table.

${ }^{b}$ Gross household income reported in Australian Dollars per annum, for all people in the household before tax, including all wages, salary, pensions and allowances. Low income $<\$ 60,000$ AUD per annum, mid income $=\$ 60,001-\$ 100,000$ AUD per annum, high income $>\$ 100,000$ AUD per annum.

$c n=36$ missing responses for income; participants responses 'refused to answer' or 'unsure'.

${ }^{\mathrm{d}} \mathrm{SEIFA}=$ Socioeconomic Index for Areas, area-level measure of SES using determined for postal code.

'Mother's occupation coded into eight categories according to Australian and New Zealand Standard Classification of Occupations (ANZSCO). Additional category created for not in the labour force = individuals engaged in full-time home duties, retired persons, unemployed and students.

$\mathrm{f} n=12$ missing responses for mother's occupation; participants did not provide sufficient information to enable accurate coding of occupation. 


\section{Socioeconomic differences in dietary intake scores}

Differences in dietary intake by SEP were found for all outcomes except girls' healthy behaviours which were predicted only by marital status, with girls from twoparent families likely to engage in more healthy behaviours (Table 3). In general, mother's education appeared to be the most consistent and strongest SEP predictor, and SEIFA was least frequently predictive of children's dietary intake. In most instances, lower SEP was associated with poorer dietary outcomes, except for girls' fruit intake. Overall the variance explained by socioeconomic factors was low, ranging from $0.5 \%-2.2 \%$ for healthy dietary intake outcomes (Table 3), and $0.6 \%-4.9 \%$ for unhealthy dietary intake (Table 4). In the strongest model explaining the most variance, all five SEP factors, mother's age and marital status explained $4.9 \%$ of variance in girls' sweetened drink intake.

Fruit intake was predicted by all SEP variables for both genders. In boys, higher fruit intake was associated with living in a more advantaged area (higher SEIFA), higher maternal education, higher household income, employment in a lower status occupation and mothers not employed in the labour force. Girls had a higher fruit intake if mothers were employed in a higher status

Table 3 Results of correlated component regression analyses for healthy dietary intake outcome measures

\begin{tabular}{|c|c|c|c|c|c|c|c|}
\hline \multicolumn{4}{|c|}{ BOYS ( $n=275)$} & \multicolumn{4}{|c|}{ GIRLS ( $n=353)$} \\
\hline Variable & $\begin{array}{c}\text { CV predictor } \\
\text { count }^{\mathrm{a}}\end{array}$ & $\beta$ & $\begin{array}{l}\text { Model goodness of } \\
\text { fit indices }\end{array}$ & Variable & $\begin{array}{c}\text { CV predictor } \\
\text { count }^{\mathrm{a}}\end{array}$ & $\beta$ & $\begin{array}{l}\text { Model goodness of } \\
\text { fit indices }\end{array}$ \\
\hline \multicolumn{4}{|l|}{ Fruit intake (8 predictors) } & \multicolumn{4}{|l|}{ Fruit intake (8 predictors) } \\
\hline SEIFA* & 100 & 0.138 & $R^{2}=0.052$ & Employment* & 100 & -0.122 & $R^{2}=0.014$ \\
\hline Mother's education* & 100 & 0.128 & $R^{2}(C V)=0.011$ & Child age* & 89 & -0.063 & $R^{2}(C V)=0.012$ \\
\hline Employment* & 96 & -0.087 & $\mathrm{SD}(\mathrm{CV})=0.004$ & Mother's occupation* & 89 & -0.063 & $\mathrm{SD}(\mathrm{CV})=0.009$ \\
\hline Mother's occupation* & 92 & 0.067 & & Marital status* & 82 & 0.033 & \\
\hline Marital status* & 82 & 0.044 & & Mother's education* & 77 & -0.010 & \\
\hline Mother's age* & 79 & -0.040 & & Mother's age* & 71 & -0.013 & \\
\hline Child age $^{*}$ & 64 & -0.035 & & SEIFA* & 71 & -0.002 & \\
\hline Income* & 47 & 0.024 & & Income* & 71 & -0.006 & \\
\hline \multicolumn{4}{|c|}{ Vegetable intake (1 predictor) } & \multicolumn{4}{|c|}{ Vegetable intake (1 predictor) } \\
\hline Mother's education* & 90 & 0.120 & $R^{2}=0.015$ & Employment* & 83 & -0.099 & $R^{2}=0.010$ \\
\hline SEIFA & 67 & & $R^{2}(C V)=0.007$ & Mother's education & 74 & & $R^{2}(C V)=0.005$ \\
\hline Employment & 42 & & $\mathrm{SD}(\mathrm{CV})=0.009$ & Mother's occupation & 10 & & $\mathrm{SD}(\mathrm{CV})=0.003$ \\
\hline Mother's age & 39 & & & SEIFA & 9 & & \\
\hline Child age & 22 & & & Income & 8 & & \\
\hline Income & 17 & & & Mother's age & 7 & & \\
\hline Mother's occupation & 2 & & & Child age & 5 & & \\
\hline Marital status & 1 & & & Marital status & 4 & & \\
\hline \multicolumn{4}{|c|}{ Healthy behaviours ${ }^{C}$ (4 predictors) } & \multicolumn{4}{|c|}{ Healthy behaviours ${ }^{c}$ (1 predictors) } \\
\hline Employment* & 100 & -0.116 & $R^{2}=0.036$ & Marital status* & 54 & 0.077 & $R^{2}=0.006$ \\
\hline Marital status* & 59 & 0.076 & $R^{2}(C V)=0.008$ & SEIFA & 31 & & $R^{2}(C V)=0.022$ \\
\hline Mother's occupation* & 57 & 0.082 & $\mathrm{SD}(\mathrm{CV})=0.004$ & Child age & 16 & & $\mathrm{SD}(\mathrm{CV})=0.013$ \\
\hline Mother's education* & 48 & 0.062 & & Mother's age & 12 & & \\
\hline Income & 12 & & & Mother's occupation & 10 & & \\
\hline SEIFA & 3 & & & Income & 3 & & \\
\hline Mother's age & 1 & & & Employment & 3 & & \\
\hline Child age $^{\wedge}$ & - & & & Mother's education & 1 & & \\
\hline
\end{tabular}

*Predictor retained in final model.

${ }^{\wedge}$ Predictor not retained in any model.

$B=$ standardised regression coefficient.

${ }^{a}$ Cross-validation predictor count - Represents number of regressions in which predictor appeared. Predictor count of 100 indicates that predictor was present in all 100 regressions. Indicates importance of predictor together with standardised regression coefficient $(\beta)$.

${ }^{b}$ Model goodness of fit indices: $R^{2}(C V)=$ cross-validated $R^{2} ; S D(C V)=$ Standard deviation for cross-validated $R^{2}$.

'Healthy behaviours: Breakfast intake, carrying water bottle, help parents with groceries, help to prepare dinner, eat dinner with the family. 
Table 4 Results of correlated component regression analyses for unhealthy dietary intake outcome measures

\begin{tabular}{|c|c|c|c|c|c|c|c|}
\hline \multicolumn{4}{|c|}{ BOYS $(n=275)$} & \multicolumn{4}{|c|}{ GIRLS $(n=353)$} \\
\hline Variable & $\begin{array}{l}\text { CV predictor } \\
\text { count }^{\mathrm{a}}\end{array}$ & $\beta$ & $\begin{array}{l}\text { Model goodness of } \\
\text { fit indices }\end{array}$ & Variable & $\begin{array}{l}\text { CV predictor } \\
\text { count }^{\mathrm{a}}\end{array}$ & $\beta$ & $\begin{array}{l}\text { Model goodness of } \\
\text { fit indices }\end{array}$ \\
\hline \multicolumn{4}{|c|}{ Non-core food intake (1 predictor) } & \multicolumn{4}{|c|}{ Non-core food intake (1 predictor) } \\
\hline Mother's education* & 62 & -0.111 & $R^{2}=0.012$ & Mother's education* & 100 & -0.119 & $R^{2}=0.012$ \\
\hline Employment & 35 & & $R^{2}(C V)=0.011$ & Marital status & 22 & & $R^{2}(C V)=0.006$ \\
\hline Marital status & 21 & & $\mathrm{SD}(\mathrm{CV})=0.008$ & Employment & 8 & & $\mathrm{SD}(\mathrm{CV})=0.003$ \\
\hline Mother's age & 20 & & & Income & 7 & & \\
\hline Income & 12 & & & Mother's occupation & 6 & & \\
\hline Child age & 10 & & & SEIFA & 3 & & \\
\hline SEIFA & 10 & & & Child age & 2 & & \\
\hline Mother's occupation & 10 & & & Mother's age & 2 & & \\
\hline \multicolumn{4}{|c|}{ Sweetened drink intake (6 predictors) } & \multicolumn{4}{|c|}{ Sweetened drink intake (7 predictors) } \\
\hline Child age $^{*}$ & 90 & 0.087 & $R^{2}=0.037$ & Income* & 100 & -0.085 & $R^{2}=0.069$ \\
\hline Mother's occupation* & 79 & 0.070 & $R^{2}(C V)=0.008$ & Mother's education* & 100 & -0.063 & $\mathrm{R}^{2}(\mathrm{CV})=0.049$ \\
\hline SEIFA* & 78 & -0.070 & $\mathrm{SD}(\mathrm{CV})=0.005$ & Employment* & 100 & -0.067 & $\mathrm{SD}(\mathrm{CV})=0.005$ \\
\hline Mother's age* & 71 & -0.051 & & Mother's age* & 100 & -0.066 & \\
\hline Income* & 70 & -0.057 & & SEIFA* & 99 & -0.064 & \\
\hline Employment* & 66 & -0.048 & & Mother's occupation* & 71 & 0.049 & \\
\hline Mother's education & 34 & & & Marital status* & 70 & -0.045 & \\
\hline Marital status & 32 & & & Child age^ & - & & \\
\hline \multicolumn{4}{|c|}{ Unhealthy behaviours ${ }^{\mathrm{C}}$ (4 predictors) } & \multicolumn{4}{|c|}{ Unhealthy behaviours ${ }^{\mathrm{C}}$ (3 predictors) } \\
\hline Child age* & 100 & 0.128 & $R^{2}=0.063$ & Mother's education* & 100 & -0.184 & $R^{2}=0.063$ \\
\hline Mother's education* & 100 & -0.121 & $R^{2}(C V)=0.037$ & Mother's occupation* & 100 & -0.149 & $R^{2}(C V)=0.039$ \\
\hline Mother's occupation* & 90 & 0.088 & $\mathrm{SD}(\mathrm{CV})=0.005$ & Employment* & 100 & -0.255 & $\mathrm{SD}(\mathrm{CV})=0.003$ \\
\hline Income* & 87 & -0.084 & & Mother's age & 20 & & \\
\hline Employment & 3 & & & Marital status & 20 & & \\
\hline SEIFA $^{\wedge}$ & - & & & Child age & 19 & & \\
\hline Mother's age & - & & & Income & 18 & & \\
\hline Marital status^ & - & & & SEIFA & 3 & & \\
\hline
\end{tabular}

*Predictor retained in final model.

Predictor not retained in any model.

$B=$ standardised regression coefficient.

${ }^{a}$ Cross-validation predictor count - Represents number of regressions in which predictor appeared. Predictor count of 100 indicates that predictor was present in all 100 regressions. Indicates importance of predictor together with standardised regression coefficient $(\beta)$.

${ }^{b}$ Model goodness of fit indices: $R^{2}(C V)=$ cross-validated $R^{2}$; SD $(C V)=$ Standard deviation for cross-validated $R^{2}$.

'Unhealthy behaviours: Eat dinner in front of TV, Eat snacks in front of TV, Eat fast food.

occupation or were not in the labour force, but also if their mothers had lower education attainment, they lived in a more disadvantaged area or had a lower household income. Higher vegetable intake was predicted by higher maternal education in boys, and mothers not employed in the labour force in girls. Engagement in more healthy eating behaviours in boys was predicted by mothers not employed in the labour force, employment in a lower status occupation and higher maternal education attainment.

Non-core food intake for boys and girls was predicted by mother's education, with children of low educated mothers having higher non-core food intake. Boys consumed more sweetened drinks if mothers were employed in lower status occupations or not in the labour force, if they lived in more disadvantaged areas, and had a lower household income. Higher sweetened drink intake among girls was predicted by lower household income, lower education attainment, not being in the labour force, living in a more disadvantaged area and employment in a lower status occupation. Boys engaged in more unhealthy behaviours if their mothers had a lower education, were employed in a lower status occupation and had a lower income. For girls, more unhealthy behaviours 
were associated with lower maternal education, employment in a lower status occupation and not being in the labour force.

\section{Discussion}

This study explored the role of five socioeconomic indicators in explaining socioeconomic differences in children's diets, finding that each indicator was independently associated with at least one dietary outcome. In general, lower SEP was associated with poorer dietary behaviours, specifically higher intake of non-core foods, sweet drinks and more unhealthy behaviours; and lower intake of fruits, vegetables and less healthy behaviours. This is consistent with previous reports of socioeconomic gradients in children's dietary intake $[2-6,34,35]$. Overall, the amount of variance explained by predictive CCR models was small, highlighting that a range of other factors are also important for children's dietary intake.

However, this effect size is consistent with the magnitude of variance in children's dietary intake explained by socio-demographic factors alone in other studies [36]. The dietary intake of children in this study did not meet suggested dietary targets, and the small differences in dietary intake between children of different socioeconomic groups suggest that all children, irrespective of SEP, would benefit from health promotion to improve dietary intake. However the necessity to target improvements in diets of low SEP children should not be dismissed. Socioeconomically-related differences in the diets of adults are generally larger than those identified for children $[37,38]$, which may be attributed to declines to dietary quality during adolescence and therefore low SEP children are an important target group to improve eating habits before declines in dietary quality during adolescence and adulthood [39]. The effect of SEP appeared to be particularly important for girls' sweetened drink intake, which was significantly and negatively associated with all measured SEP variables. This is in contrast to another study which found SEP predicted boys', but not girls' soft drink consumption [18]. A target area for future nutrition promotion may be encouraging the reduction of sweetened drink intake among low SEP children.

The effect of SEP differed between boys and girls, consistent with previous studies $[4,18]$. In particular, gender differences were identified in associations of fruit intake with SEP. In contrast to boys, fruit intake was higher among girls of low educated mothers, low income households and living in more disadvantaged neighbourhoods. This finding is difficult to explain and requires further investigation. Fruit, unlike vegetables, typically requires little preparation or cooking skills, and may be perceived as an easy to consume snack $[40,41]$. Low SEP women have reported lower levels of food preparation and cooking skills [42], and so might be more likely to provide fruit for a handy snack or part of a meal. If so, it is unclear why this was the case only for girls and not boys. Alternatively, these findings may be due to more general gender stereotypes around food, eating and health. From an early age, girls are socialised differently with regard to food and this may result in more health consciousness, more weight concerns, and different health beliefs and attitudes, which are translated into different dietary patterns [43-45]. Girls may perceive their food environments differently to boys, reporting more restrictions around eating than boys, despite parent reports indicating no differences in rule imposition between boys and girls [46]. However, it is unclear how SEP may impact on gender stereotypes around eating and this warrants future consideration.

Multiple socioeconomic factors independently predicted many of the dietary outcomes, suggesting the need to consider multiple socioeconomic indices when explaining gradients in children's dietary intake. To provide further insight into potential covariance and conceptual overlap among SEP indicators, adjusted bivariate CCR regression models for each individual SEP indicator and dietary outcome were conducted (results available as Additional file 1: Table S1 online). The patterning of results between adjusted bivariate associations and multivariate models was similar, however there was attenuation or amelioration of associations between SEP and diet in some multivariate models compared with bivariate associations, suggesting some overlap between SEP variables. Turrell et al. [25] similarly found that in multivariate models, independent associations of SEP indicators with food purchasing changed compared with original bivariate associations, and suggested that this attenuation occurred as a result of unmeasured effects due to overlap between SEP indicators. However, correlations between SEP indicators are weak, and Turrell et al. [25] cautioned that researchers should not assume that each SEP indicator is tapping a similar underlying construct, and therefore indicators should not be used interchangeably. Correspondingly, the findings of this study highlight a risk of misrepresenting socioeconomic gradients if only a single measure of SEP is used. The differences between adjusted bivariate associations and multivariate models suggest that had results solely relied upon bivariate associations, the claims about SEP-diet indicators would have been misstated. Over- or underestimation of socioeconomic gradients in dietary intake may have implications for the development and implementation of dietary intervention strategies or health promotion campaigns. Distinct facets of SEP may influence children's dietary intake by conceptually different pathways, and therefore inclusion of SEP variables in analyses should be driven by conceptual considerations. Further still, an individual's SEP is defined by more than one SEP variable, and these variables may each influence dietary intake differently, 
but each may also mediate associations between other SEP indicators and diet. For example, education may influence occupation and income, which may then impact on diet; in this case occupation and income would be mediating variables. Formal tests of mediation were beyond the scope of this investigation, but future studies should consider the mediating role and interplay between different SEP variables in associations of SEP and children's diet. We refer readers to Turrell et al. [25] which provides a detailed discussion of the stability and robustness of different SEP indicators in relation to adult diet. Given the evidence for the importance of each SEP indicator independently in relation to eating, in the following section we consider theoretical conceptual pathways of influence for SEP on children's diet.

Mother's education level was the most consistent predictor across all dietary outcomes. Low education was associated with higher intake of non-core foods and sweetened drinks, and more unhealthy behaviours, as well as lower vegetable intake and less healthy behaviours. Maternal education has been identified as the most consistent predictor of children's diet, and low maternal education has been associated with poorer dietary intake across a range of dietary outcomes $[1,3,5,23,34,47]$. Higher education may enable individuals to better access, assimilate and put into practice health information $[48,49]$, and may therefore better equip parents to understand and make use of health and nutrition information. Parents of lower education may have poorer nutrition knowledge [49,50], and consider health less often when making food choices for themselves and their children $[48,51]$. Conversely, parents of higher education may place more importance on healthy eating, which may be related with better nutrition knowledge [52]. Nutrition knowledge and health consideration may be related with healthier dietary intake among mothers and children, and may inform the types of foods parents provide for their family $[49,51,53,54]$.

Findings for the effect of mother's occupation and employment on children's dietary intake were mixed. On the one hand, employment in higher status occupations was associated with more fruit intake and less sweetened drink intake, consistent with previous studies $[18,19]$. Unexpectedly, boys of mothers in higher status occupations reported less fruit intake and healthy behaviours and more unhealthy behaviours. This was explored further by considering the effect of maternal employment on children's dietary intake, and we found that employment was associated with dietary intake independently of mother's occupation. Children of employed mothers were likely to consume more sweetened drinks, fewer fruits and vegetables and engage in less healthy behaviours. Time spent in employment may impact on the time mothers have to engage in activities that can positively influence children's food intake, such as supervising breakfast consumption, eating family meals and engaging children in food shopping. Time-poor mothers may be more reliant on takeaway meals, contributing to lower consumption of fruit and vegetables [1]. Neumark-Sztainer [55] reported that adolescents of unemployed mothers consumed family meals more frequently, and this was related to more positive dietary behaviours. Younger children of employed mothers had a higher sweetened drink intake and a lower likelihood of consuming fruits and vegetables as a snack [56]. Sweeting and West [23] found children of mothers in part-time employment to have a significantly lower risk for unhealthy eating, suggesting these mothers may have an economic advantage over homemakers and a time advantage over mothers who are employed full-time [23]. Occupation determines working conditions such as time spent in employment, flexibility of working arrangements and differential exposure to work place stressors, and these factors may affect children's dietary intake $[24,25]$. Given this, it is likely that a combination of factors related to both occupation and employment influence children's food intake.

This study found that higher income independently predicted more fruit intake and less sweetened drink intake and unhealthy behaviours. Income appeared less frequently as a predictor of children's dietary intake than education, occupation and employment. This is consistent with previous literature, except that previous authors have also found income to be positively associated with vegetable consumption $[1,28,35]$. Income reflects the financial resources available for food purchasing, accessing resources and health professionals. Low income families may prioritise non-food expenses such as rent/ mortgage, utility bills and school fees over food and health expenditure, as these expenses are less flexible [57], and must allocate a greater proportion of their overall income to purchasing food. Purchasing groceries according to dietary guidelines costs low income families $35-44 \%$ of their disposable income compared to approximately $20 \%$ for families of average income $[57,58]$. Purchasing patterns of low-income families indicate they may purchase fewer fruits and vegetables, foods high in fibre, low in fat, sugar and salt $[59,60]$. Healthy foods, particularly fruit and vegetables, may be perceived to be more expensive [61] and low-income adults are more likely to report price as a barrier to fruit and vegetable consumption $[62,63]$.

SEIFA appeared least frequently as a predictor of dietary intake, with an effect of smaller magnitude compared with the other socioeconomic indicators. Living in a more disadvantaged area predicted higher sweetened drink intake and more unhealthy behaviours, and lower fruit intake for boys. The types of foods readily available for purchase in close proximity to the family home may influence 
children's food consumption [64]. More access to convenience stores and fast food restaurants may contribute to higher intake of processed snack foods, displacing intake of fruits and vegetables $[65,66]$. However the evidence for disproportionate access to food stores by neighbourhood disadvantage is mixed. Studies conducted in the USA suggest that disadvantaged neighbourhoods may have fewer supermarkets and more convenience stores, resulting in higher prices and lower availability of healthy foods [67-71]. Evidence from Australian studies is less consistent, with some studies suggesting better access to supermarkets and greengrocers in more advantaged neighbourhoods [72,73], but other authors finding no difference in store availability between low and high SEP neighbourhoods [74]. Evidence of neighbourhood variation in takeaway and fast-food outlets is mixed, with studies showing no socioeconomic differences [75]; a higher density of fast-food outlets in low socioeconomic areas [76]; and conversely closer proximity to fast-food restaurants in more advantaged areas [73]. It is likely that the relationships between diet and neighbourhood are culturally and contextually specific, and may differ by region, state and country.

\section{Strengths and limitations of study}

As this study was cross-sectional causality cannot be inferred, and although cross-sectional studies offer a snapshot of current associations, factors resulting in behaviour change cannot be identified. Individual SEP may predict participation in research, with lower participation rates among individuals of low SEP, and non-responders to dietary surveys may also differ from responders on dietary intake and attitudes $[77,78]$. This indicates a risk of a recruitment bias, whereby parents more 'concerned' about health and nutrition may have opted to participate which may have influenced the types of responses in questionnaires. However, parents were offered a $\$ 30$ voucher as compensation for time taken to participate in the study, to encourage some parents to participate who may not have otherwise done so. There were no differences in scores reported for dietary intake between children who did and did not participate in phase two; however families who participated in phase two resided in neighbourhoods of higher SEP than those who did not. This potential respondent bias must be recognised as a limitation of this study, despite achieving a socioeconomically stratified participant sample and providing incentives for participation. Finally, the limitations of children reporting their own dietary intake need to be recognised, in terms of reporting errors and poorer recall of intake. However, the CNQ has been shown to have acceptable validity and reliability in children of this age group [27] and children of this age are capable of self-reporting dietary intake [79]. The strengths of this study include the relatively even distribution of the sample across socioeconomic strata. Multiple dimensions of SEP were considered simultaneously, allowing for independent and shared effects of demographic variables to be determined. Analyses were conducted separately for boys and girls, enabling the identification of sex-specific socioeconomic predictors of dietary intake. SEP data were not reduced into broad categories for analysis (i.e. low versus high), therefore increasing the sensitivity to detecting gradients across SEP strata. Online administration of the CNQ allowed for in-built measures, such as forced question response, to minimise missing data and reduce errors associated with data entry.

\section{Conclusions}

Education, occupation/employment, income and to a lesser extent SEIFA were all associated with children's dietary intake, in most situations (except girls' fruit intake) with low SEP being associated with poorer dietary outcomes. Varying associations of SEP with diet were observed across different indicators of both SEP and diet, suggesting that different components of SEP may affect children's eating differently, and therefore researchers should consider multiple SEP indicators when defining SEP in relation to children's eating.

By conducting multivariate models, we were able to identify that education, occupation and income are all independently associated with various indices of children's dietary intake, and that the nature of the association of SEP with diet differs according to children's gender and the dietary outcome in question.

\section{Additional file}

Additional file 1: Table S1. Bivariate models of associations of socioeconomic indicators with children's dietary intake.

\section{Competing interests}

The authors' declare that they have no competing interests.

\section{Authors' contributions}

In addition to specific contributions listed below, all authors contributed to the study design, statistical analysis and interpretation of the data. DZ carried out data collection and drafted the manuscript. KB, NP and JD revised the manuscript. With the assistance of a statistician, DZ conceptualised and conducted the statistical analysis. All authors read and approved the final manuscript.

\section{Acknowledgements}

We acknowledge the contribution of Keren Kneebone who coordinated the study and conducted data collection. The authors would also like to acknowledge the schools, children and parents who gave their time to participate in this research. John Petkov, a much loved and respected statistician, sadly passed away in January 2013. We are very grateful for his contribution to this study and for his generous mentorship over the years. This study was supported by an ARC Linkage Grant with SA Health (\# LP 0883949). The Funding source was not involved in the preparation or submission of this research report. KB is supported by a NHMRC Principal Research Fellowship, ID 1042442. NP is supported by National Health and Medical Research Council Program Grant funding (\# 320860 and 631947). 


\section{Author details}

'School of Population Health, University of South Australia, GPO Box 2471, Adelaide, SA 5001, Australia. ${ }^{2}$ School of Nutrition and Exercise Science, Deakin University, Burwood Highway, Burwood, VIC3125, Australia. ${ }^{3}$ School of Health Sciences, University of South Australia, GPO Box 2471, Adelaide, SA 5001, Australia.

Received: 10 May 2013 Accepted: 17 March 2014

Published: 28 March 2014

\section{References}

1. Rasmussen M, Krølner R, Klepp K, Lytle L, Brug J, Bere E, Due P: Determinants of fruit and vegetable consumption among children and adolescents: a review of the literature. Part I: quantitative studies. Int J Behav Nutr Phys Act 2006, 3:22.

2. Stephens LDA, McNaughton SA, Crawford D, MacFarlane A, Ball K: Correlates of dietary resilience amongst socioeconomically disadvantaged adolescents. Eur J Clin Nutr 2011, 65:1219-1232.

3. Nilsen SM, Krokstad S, Holmen TL, Westin S: Adolescents' health-related dietary patterns by parental socio-economic position, The NordTrøndelag Health Study (HUNT). Eur J Public Health 2010, 20:299-305.

4. Craig LCA, McNeill G, Macdiarmid JI, Masson LF, Holmes BA: Dietary patterns of school-age children in Scotland: association with socioeconomic indicators, physical activity and obesity. Br J Nutr 2010, 103:319-334.

5. Ball K, MacFarlane A, Crawford D, Savige G, Andrianopoulos N, Worsley A: Can social cognitive theory constructs explain socio-economic variations in adolescent eating behaviours? A mediation analysis. Health Educ Res 2009, 24:496-506.

6. Golley RK, Hendrie GA, McNaughton SA: Scores on the dietary guideline index for children and adolescents are associated with nutrient intake and socio-economic position but not adiposity. J Nutr 2011, 141:1340-1347.

7. Shrewsbury V, Wardle J: Socioeconomic status and adiposity in childhood: a Systematic review of cross-sectional studies 1990-2005. Obesity 2008, 16:275-284

8. Pollitt R, Rose K, Kaufman J: Evaluating the evidence for models of life course socioeconomic factors and cardiovascular outcomes: a systematic review. BMC Public Health 2005, 5:7.

9. Hanson NI, Neumark-Sztainer D, Eisenberg ME, Story M, Wall M: Associations between parental report of the home food environment and adolescent intakes of fruits, vegetables and dairy foods. Public Health Nutr 2005, 8:77-85.

10. Cartwright M, Wardle J, Steggles N, Simon AE, Croker H, Jarvis MJ: Stress and dietary practices in adolescents. Health Psychol 2003, 22:362-369.

11. Janssen I, Boyce WF, Simpson K, Pickett W: Influence of individual- and area-level measures of socioeconomic status on obesity, unhealthy eating, and physical inactivity in Canadian adolescents. Am J Clin Nutr 2006, 83:139-145.

12. Bunting $G$, Freeman $R$ : The influence of socio-demographic factors upon children's breaktime food consumption in North and West Belfast. Health Educ J 1999, 58:401-409.

13. Fahlman MM, McCaughtry N, Martin J, Shen B: Racial and socioeconomic disparities in nutrition behaviors: targeted interventions needed. J Nutr Educ Behav 2010, 42:10-16.

14. Hallstrom L, Vereecken CA, Ruiz JR, Patterson E, Gilbert CC, Catasta G, Diaz L-E, Gomez-Martinez S, Gonzalez Gross M, Gottrand F, Hegyi A, Lehoux C, Mouratidou T, Widham K, Astrom A, Moreno LA, Sjostrom M: Breakfast habits and factors influencing food choices at breakfast in relation to socio-demographic and family factors among European adolescents. The HELENA Study. Appetite 2011, 56:649-657.

15. Inchley J, Todd J, Bryce C, Currie C: Dietary trends among Scottish schoolchildren in the 1990s. J Hum Nutr Diet 2001, 14:207-216.

16. Cutler GJ, Flood A, Hannan P, Neumark-Sztainer D: Multiple sociodemographic and socioenvironmental characteristics are correlated with major patterns of dietary intake in adolescents. J Am Diet Assoc 2011, 111:230-240.

17. Lien N, Lytle LA, Komro KA: Applying theory of planned behavior to fruit and vegetable consumption of young adolescents. Am J Health Promot 2002, 16:189-197.
18. Haerens L, Craeynest M, Deforche B, Maes L, Cardon G, De Bourdeaudhuij I: The contribution of psychosocial and home environmental factors in explaining eating behaviours in adolescents. Eur J Clin Nutr 2008, 62:51-59.

19. Sandvik C, Gjestad R, Samdal O, Brug J, Klepp K-I: Does socio-economic status moderate the associations between psychosocial predictors and fruit intake in schoolchildren? The Pro Children study. Health Educ Res 2010, 25:121-134.

20. Liberatos $P$, Link B, Kelsey J: The measurement of social class in epidemiology. Epidemiol Rev 1988, 10:87-121.

21. Lallukka T, Laaksonen M, Rahkonen O, Roos E, Lahelma E: Multiple socio-economic circumstances and healthy food habits. Eur I Clin Nutr 2007, 61:701-710.

22. Vereecken CA, Inchley J, Subramanian SV, Hublet A, Maes L: The relative influence of individual and contestual socio-economic status on consumption of fruit and soft drinks among adolescents in Europe. Eur J Public Health 2005, 15:224-232.

23. Sweeting $H$, West P: Dietary habits and children's family lives. I Hum Nutr Diet 2005, 18:93-97.

24. Galobardes B, Morabia A, Bernstein MS: Diet and socioeconomic position: does the use of different indicators matter? Int J Epidemiol 2001, 30:334-340.

25. Turrell G, Hewitt B, Patterson C, Oldenburg B: Measuring socio-economic position in dietary research: is choice of socio-economic indicator important? Public Health Nutr 2003, 6:191-200.

26. Geyer S, Hemström Ö, Peter R, Vågerö D: Education, income, and occupational class cannot be used interchangeably in social epidemiology. Empirical evidence against a common practice. J Epidemiol Community Health 2006, 60:804-810.

27. Wilson A, Magarey A, Mastersson N: Reliability and relative validity of a child nutrition questionnaire to simultaneously assess dietary patterns associated with positive energy balance and food behaviours, attitudes, knowledge and environments associated with healthy eating. Int I Behav Nutr Phys Act 2008, 5:5-17.

28. Vereecken $C A$, Maes $L$ : $A$ Belgian study on the reliability and relative validity of the Health Behaviour in School-Aged Children food-frequency questionnaire. Public Health Nutr 2003, 6:581-588.

29. Andersen LF, Bere E, Kolbjornsen N, Klepp KI: Validity and reproducibility of self-reported intake of fruit and vegetable among 6th graders. Eur J Clin Nutr 2004, 58:771-777.

30. Hannon P, Bowen D, Moinpour C, McLerran D: Correlations in perceived food use between the family food preparer and their spouses and children. Appetite 2003, 40:77-83.

31. Australian Bureau of Statistics: Australian and New Zealand Standard Classification of Occupations (ANZSCO) First Edition ABS Cat. No. 1220.0. Canberra, Australia: Australian Bureau of Statistics; 2006.

32. Magidson J: Correlated component regression: a prediction/classification methodology for possibly many features. In American Statistical Association Proceedings. American Statistical Association; 2010.

33. Department of Health and Ageing: The Australian Guide to Healthy Eating Canberra: ACT: Australian Government; 2010.

34. Ambrosini GL, Oddy WH, Robinson M, O'Sullivan TA, Hands BP, de Klerk NH, Silburn SR, Zubrick SR, Kendall GE, Stanley FJ, Beilin L: Adolescent dietary patterns are associated with lifestyle and family psycho-social factors. Public Health Nutr 2009, 12:1807-1815.

35. Bere E, van Lenthe F, Klepp K-I, Brug J: Why do parents' education level and income affect the amount of fruits and vegetables adolescents eat? Eur J Public Health 2008, 18:611-615.

36. Kristjansdottir AG, Thorsdottir I, De Bourdeaudhuij I, Due P, Wind M Klepp Kl: Determinants of fruit and vegetable intake among 11-year-old schoolchildren in a country of traditionally low fruit and vegetable consumption. Int J Behav Nutr Phys Act 2006, 3:41-49.

37. De Irala-Estevez J, Groth $M$, Johansson L, Oltersdorf U, Prattala R, MartinezGonzalez M: A systematic review of socio-economic differences in food habits in Europe: consumption of fruit and vegetables. Eur J Clin Nutr 2000, 54:706-714.

38. Giskes K, Turrell G, Patterson C, Newman B: Socioeconomic differences among Australian adults in consumption of fruit and vegetables and intakes of vitamins A, C and folate. J Hum Nutr Diet 2002, 15:375-385.

39. Lien N, Lytle L, Klepp K: Stability in consumption of fruit, vegetables, and sugary foods in a cohort from age 14 to age 21. Prev Med 2001, 33:217-226. 
40. Brug J, Debie S, van Assema P, Weijts W: Psychosocial determinants of fruit and vegetable consumption among adults: Results of focus group interviews. Food Qual Prefer 1995, 6:99-107.

41. Heimendinger J, Van Duyn MA: Dietary behavior change: the challenge of recasting the role of fruit and vegetables in the American diet. Am J Clin Nutr 1995, 61:1397S-1401S

42. Williams L, Ball K, Crawford D: Why do some socioeconomically disadvantaged women eat better than others? An investigation of the personal, social and environmental correlates of fruit and vegetable consumption. Appetite 2010, 55:441-446.

43. Cohen RY, Brownell KD, Felix MR: Age and sex differences in health habits and beliefs of schoolchildren. Health Psychol 1990, 9:208-224.

44. O'Dea JA, Caputi P: Association between socioeconomic status, weight, age and gender, and the body image and weight control practices of 6- to 19-year-old children and adolescents. Health Educ Res 2001, 16:521-532.

45. Wardle J, Haase A, Steptoe A, Nillapun M, Jonwutiwes K, Bellisie F: Gender differences in food choice: the contribution of health beliefs and dieting. Ann Behav Med 2004, 27:107-116.

46. De Bourdeaudhuij I: Family food rules and healthy eating in adolescents. J Health Psychol 1997, 2:45

47. Aranceta J, Perez-Rodrigo C, Ribas L, Serra-Majem L: Sociodemographic and lifestyle determinants of food patterns in Spanish children and adolescents: the enKid study. Eur J Clin Nutr 2003, 57(Suppl 1):S40-S44.

48. Ball K, Crawford D: Socio-economic factors in obesity: a case of slim chance in a fat world? Review article. Asia Pac J Clin Nutr 2006, 15:15-20.

49. Parmenter K, Waller J, Wardle J: Demographic variation in nutrition knowledge in England. Health Educ Res 2000, 15:163-174.

50. Hendrie GA, Coveney J, Cox D: Exploring nutrition knowledge and the demographic variation in knowledge levels in an Australian community sample. Public Health Nutr 2008, 11:1365-1372.

51. Hupkens CLH, Knibbe RA, Drop MJ: Social class differences in food consumption: The explanatory value of permissiveness and health and cost considerations. Eur J Public Health 2000, 10:108-113.

52. Zarnowiecki D, Sinn N, Petkov J, Dollman J: Parental nutrition knowledge and attitudes as predictors of 5-6-year-old children's healthy food knowledge. Public Health Nutr 2011, 15:1284-1290.

53. Gibson EL, Wardle J, Watts CJ: Fruit and vegetable consumption, nutritional knowledge and beliefs in mothers and children. Appetite 1998, 31:205-228

54. Variyam J, Blaylock J, Lin B, Ralston K, Smallwood D: Mother's nutrition knowledge and children's dietary intakes. Am J Agr Econ 1999, 81:373-384.

55. Neumark-Sztainer D, Hannan PJ, Story M, Croll J, Perry C: Family meal patterns: Associations with sociodemographic characteristics and improved dietary intake among adolescents. J Am Diet Assoc 2003, 103:317-322.

56. Hawkins SS, Cole TJ, Law C: Examining the relationship between maternal employment and health behaviours in 5-year-old British children. J Epidemiol Community Health 2009, 63:999-1004.

57. Kettings C, Sinclair AJ, Voevodin M: A healthy diet consistent with Australian health recommendations is too expensive for welfare-dependent families. Aust N Z J Public Health 2009, 33:566-572.

58. Tsang A, Ndung'U M, Coveney J, O'Dwyer L: Adelaide healthy food basket: A survey on food cost, availability and affordability in five local government areas in metropolitan Adelaide, South Australia. Nutr Diet 2007, 64:241-247

59. Giskes K, Van Lenthe FJ, Brug J, Mackenbach JP, Turrell G: Socioeconomic inequalities in food purchasing: The contribution of respondent-perceived and actual (objectively measured) price and availability of foods. Prev Med 2007, 45:41-48

60. Turrell G, Hewitt B, Patterson C, Oldenburg B, Gould T: Socioeconomic differences in food purchasing behaviour and suggested implications for diet-related health promotion. J Hum Nutr Diet 2002, 15:355.

61. McGee BB, Johnson GS, Yadrick MK, Richardson V, Simpson PM, Gossett JM, Thornton A, Johnson C, Bogle ML: Food Shopping Perceptions, Behaviors, and Ability to Purchase Healthful Food Items in the Lower Mississippi Delta. J Nutr Educ Behav 2011, 43:339-348.

62. Giskes K, Turrell G, Patterson C, Newman B: Socio-economic differences in fruit and vegetable consumption among Australian adolescents and adults. Public Health Nutr 2002, 5:663-669.

63. Inglis V, Ball K, Crawford D: Why do women of low socioeconomic status have poorer dietary behaviours than women of higher socioeconomic status? A qualitative exploration. Appetite 2005, 45:334-343.
64. Sallis JF, Glanz K: The role of built environments in physical activity, eating, and obesity in childhood. Futur Child 2006, 16(1):89-108.

65. Jago R, Baranowski T, Baranowski J, Cullen K, Thompson D: Distance to food stores \& adolescent male fruit and vegetable consumption: mediation effects. Int J Behav Nutr Phys Act 2007, 4:35

66. Timperio A, Ball K, Roberts R, Campbell K, Andrianopoulos N, Crawford D: Children's fruit and vegetable intake: associations with the neighbourhood food environment. Prev Med 2008, 46:331-335.

67. Franco M, Diez Roux AV, Glass TA, Caballero B, Brancati FL: Neighborhood characteristics and availability of healthy foods in Baltimore. Am J Prev Med 2008, 35:561-567.

68. Moore L, Diez Roux A: Associations of neighborhood characteristics with the location and type of food stores. Am J Public Health 2006, 96:325-331.

69. Moore LV, Diez Roux AV, Nettleton JA, Jacobs DR: Associations of the local food environment with diet quality-a comparison of assessments based on surveys and geographic information systems. Am J Epidemiol 2008, 167:917-924

70. Morland K, Wing S, Diez Roux A, Poole C: Neighborhood characteristics associated with the location of food stores and food service places. Am J Prev Med 2002, 22:23-29.

71. Powell LM, Slater S, Mirtcheva D, Bao Y, Chaloupka FJ: Food store availability and neighborhood characteristics in the United States. Prev Med 2007, 44:189-195.

72. Ball K, Timperio A, Crawford D: Neighbourhood socioeconomic inequalities in food access and affordability. Health Place 2009, 15:578-585.

73. Thornton LE, Crawford DA, Ball K: Neighbourhood-socioeconomic variation in women's diet: the role of nutrition environments. Eur J Clin Nutr 2010, 64:1423-1432

74. Winkler $\mathrm{E}$, Turrell G, Patterson C: Does living in a disadvantaged area mean fewer opportunities to purchase fresh fruit and vegetables in the area? Findings from the Brisbane food study. Health Place 2006, 12:306-319.

75. Turrell G, Giskes K: Socioeconomic disadvantage and the purchase of takeaway food: A multilevel analysis. Appetite 2008, 51:69-81.

76. Reidpath D, Burns C, Garrard J, Mahoney M, Townsend M: An ecological study of the relationship between social and environmental determinants of obesity. Health Place 2002, 8:141-145.

77. Berg C, Jonsson I, Conner MT, Lissner L: Sources of bias in a dietary survey of children. Eur J Clin Nutr 1998, 52:663-667.

78. Turrell G, Patterson C, Oldenburg B, Gould T, Roy M-A: The socio-economic patterning of survey participation and non-response error in a multilevel study of food purchasing behaviour: area- and individual-level characteristics. Public Health Nutr 2003, 6:181-189.

79. Baranowski T, Domel SB: A cognitive model of children's reporting of food intake. Am J Clin Nutr 1994, 59:212S-212S.

\section{doi:10.1186/1479-5868-11-44}

Cite this article as: Zarnowiecki et al:: Describing socioeconomic gradients in children's diets - does the socioeconomic indicator used matter? International Journal of Behavioral Nutrition and Physical Activity 2014 11:44.

\section{Submit your next manuscript to BioMed Central and take full advantage of:}

- Convenient online submission

- Thorough peer review

- No space constraints or color figure charges

- Immediate publication on acceptance

- Inclusion in PubMed, CAS, Scopus and Google Scholar

- Research which is freely available for redistribution 